\title{
"It's important to take your medication everyday okay?" An evaluation of counselling by lay counsellors for ARV adherence support in the Western Cape, South Africa
}

\section{S. Dewing • C. Mathews • N. Schaay $\bullet$}

\section{A. Cloete $\bullet J$. Louw $\bullet$ L. Simbayi}

\begin{abstract}
There is growing interest in standard care programmes for antiretroviral (ARV) adherence support. In South Africa, individual counselling following ARV initiation is a main strategy for supporting adherence in the public sector. Egan's client-centred "Skilled Helper" counselling model is the predominant model used in HIV counselling in this context. This study evaluated counselling delivered by lay ARV adherence counsellors in Cape Town in terms of adherence to Egan's model. Thirty-eight transcripts of counselling sessions with non-adherent patients were analysed based on the methods of content analysis. These sessions were conducted by 30 counsellors. Generally counsellors' practice adhered neither to Egan's model nor a client-centred approach. Inconsistent with evidence-based approaches to counselling for ARV adherence support, counsellors mainly used information- giving and advice as strategies for addressing clients' non- adherence. Recommendations for improving practice are made. The question as to how appropriate strategies from developed countries are for this setting is also raised.
\end{abstract}

S. Dewing $(\&) \cdot$ C. Mathews

Health Systems Research Unit, Medical Research Council, P. O. Box 19070, Tygerberg, Cape Town 7505, South Africa e-mail: sarahdewing@gmail.com

C. Mathews

School of Public Health and Family Medicine, University of Cape Town, Cape Town 7925, South Africa

N. Schaay

School of Public Health, University of the Western Cape, Cape Town 7535, South Africa

A. Cloete $\bullet$ L. Simbayi

HIV/AIDS, STIs and TB Research Programme, Human Sciences Research Council, Cape Town 8000, South Africa

J. Louw

Department of Psychology, University of Cape Town, Cape Town 7701, South Africa

Keywords Standard care • Antiretroviral adherence support • Counselling • Egan's skilled helper model

\section{Introduction}

The implications of antiretroviral (ARV) non-adherence for individual and public health are well-documented (e.g. 1-3), and sustained high levels of adherence are required in order for 
the maximum benefits of ARV therapy to be achieved [4,5]. Monitoring and support for ARV adherence are thus recognised as important components of HIV care [6, 7]. Much research has focused on the development and efficacy of interventions for supporting adherence to long-term medications including ARVs. Several types of interventions have been shown to improve adherence, although improvements are small and few significantly affect treatment outcomes [8-10]. Successful interventions have been observed to share commonalities in delivery systems; these are most commonly patient-centred and incorporate specific strategies associated with motivational interviewing, cognitive behavioural therapy or learner- based models [11]. Successful patient support and education strategies have been identified in a review of studies conducted in the United States, Europe and Australia [12]. Strategies targeting practical medication management skills are more successful in terms of adherence outcomes than interventions based on cognitive behavioural therapy and motivational interviewing approaches [12]. In general practical medication management interventions are aimed at improving participants' ability to manage their treatment, and focus on medication information, tailored drug schedules, side-effect management and the use of reminders. In addition, patients are assisted in identifying and addressing barriers to adherence [12]. Other features of successful strategies include delivery to individuals as opposed to groups and delivery over longer periods (12 weeks or more) of time [12].

Barnighausen et al. [13] suggest that evidence from the developed world may have limited relevance in sub- Saharan Africa (SSA) however, as the context in which an intervention is implemented is likely to affect its efficacy. For example they argue that theories of behaviour from developed countries may not be valid in SSA, and observe that adherence interventions in SSA are also often not delivered by professional health workers such as physicians, pharmacists and nurses. Their review of ARV adherence intervention studies conducted in SSA suggests that interventions successful in this context include the use of reminders, treatment supporters, directly observed therapy, education and counselling, and food rations [13].

There appears to be a growing interest in standard care (SC) programmes for adherence support, to the extent that it has been suggested that an understanding of such programmes could inform the development of evidence-based interventions that are responsive to the circumstances in which they are to be implemented [6]. Generally SC programmes for ARV adherence support have not been targeted for evaluation as interventions in their own right, but they do appear in the literature as comparison controls in ARV adherence intervention trials. In a review of the quality of SC provided in such trials, de Bruin et al. [14] found higher levels of quality of SC to be related to positive treatment outcomes. While the kind and quality of SC was found to vary considerably between studies, their findings indicate that SC for adherence support can be effective [14]. Individual counselling for adherence support has been identified as one of the more common strategies adopted by HIV treatment programmes both in the United States [6] and Africa [15, 16]. The content and approach of these interventions varies widely, and the extent to which busy clinics and health care providers are able to effectively incorporate counselling into clinical care is not well established [7].

In resource-limited settings such as SSA, healthcare interventions are often delivered by lay health workers [17]. Lay health workers are people with no formal professional or 
paraprofessional certificate or degree in tertiary education, but who carry out functions related to health care delivery and are trained in the context of the healthcare intervention [17]. While there is evidence that lay health workers can effectively deliver health care interventions for some health issues (e.g. immunisation, respiratory infections, malaria) [17], few studies have evaluated lay counsellors' ability to implement counselling techniques associated with behaviour change interventions. Two studies conducted in the Western Cape have found that lay counsellors generally do not achieve beginning proficiency in the advanced behaviour-change counselling technique of motivational interviewing [18, 19]. The current study was conducted as a part of a larger study in which lay counsellors were trained to implement an evidence-based behaviour change intervention called Options for Health: Western Cape. This paper presents data relating to the evaluation of SC counselling for ARV adherence support delivered by lay counsellors located within primary health care clinics in Cape Town.

\section{SC Counselling for ARV Adherence Support in South Africa}

In South Africa individual counselling following ARV initiation is one of the main strategies for supporting adherence in the public sector. ARV adherence counselling is a service delivered by lay counsellors within all ARV clinics in the Western Cape Province of South Africa.

Egan's "Skilled Helper" model is the predominant model used in HIV counselling in the public sector across the nine provinces of South Africa. The model represents a problem-management approach to counselling and is patient-centred [20]. The relationship between counsellor and client is one of collaboration, and the task of the counsellor is to assist the client to explore personalised alternatives and responses to their situation [20, 21]. The model is applicable to a diverse range of client issues and has been promoted internationally as a treatment method in various contexts including counselling around sexual abuse [22], careers and workplace counselling [23-25] as well as counselling within primary health care [26] and the training of nurses and health professionals [27, 28]. Despite the widespread use of this model in counselling practice, there is no research pertaining to its effectiveness as a behaviour change intervention in any setting [29]. The model does however share features with successful interventions targeting practical medication management skills mentioned above. The model is also consistent with the Centres for Disease Control and Prevention recommendation that HIV counselling be client-centred and result in a personalised plan for behaviour change [30].

The extent to which lay counsellors can adopt and implement Egan's model in relation to medication adherence is unclear, and evidence suggests that ARV adherence counselling in the Western Cape consists mainly of directive and health-advising techniques [31]. This paper describes counsellors' practice in terms of basic counselling skills and fidelity to Egan's model and a client-centred counselling approach.

\section{Setting}

Lay counsellors working within the public health care system are employed by external Non-Governmental Organisations (NGOs), and are currently trained by the Western Cape 
AIDS, Training, Information and Counselling Centre (ATICC) (http://www.westerncape.gov.za/your gov/80798). ATICC trains counsellors using a micro-skills approach. This method divides the counsellor-client interaction into small, meaningful skills used to tap into the clients' problem situation [32]. The intention is that trainees integrate these skills into the counselling framework [33], in this case Egan's model. Basic verbal counselling skills trained by ATICC are presented and defined in Table 1. An overview of Egan's 3-stage model as trained by ATICC is provided in Table 2.

Lay HIV counsellors are initially trained at ATICC in a 10 day HIV/AIDS Information Course. Participants are required to be in possession of a matric (Grade 12) certificate. After completing the information course learners are trained in a 20 day (120 h) Intensive Counselling Course. This course trains on basic counselling skills and Egan's model. Throughout each of these courses counsellors are assessed in role-plays and by means of a knowledge questionnaire (for the counselling course this includes items on counselling skills); a minimum of $60 \%$ is required to pass. The Department of Health requires all HIV counselling and testing (HCT) counsellors working in government facilities to have successfully completed both of these courses.

After qualifying in HCT, counsellors are eligible to be nominated by their NGO for participation in ATICCs' 10 day adherence counselling course. The course covers information around taking ARVs; Egan's model and basic counselling skills are not revised. Again counsellors are assessed and a minimum of $60 \%$ is required to pass. Following this, counsellors are qualified to practice as ARV adherence counsellors. Attendance of refresher training is not a requirement of NGOs or the Department of Health, and ATICC currently does not offer any such courses.

Table 1: Verbal micro-counselling skills trained at ATICC

Skill Definition

Open question

Questions encouraging explanation or expansion upon thoughts, feelings, experiences. May start with the following stems: how, tell me, in what way.

Closed question

Simple reflection Questions that can be answered with yes, no or one word phrases.

Simple reflection

Complex reflection

Repetition or rephrasing of clients words, used to check understanding or to convey understanding of what the client has said. May reflect content or feeling.

Provides a more in-depth interpretation of what the client has said, inferring unspoken meaning 
Table 2 :

An overview of Egan's Model as trained by ATICC

\begin{tabular}{|c|c|c|}
\hline Stage 1: exploration & Stage 2: understanding & Stage 3: action \\
\hline $\begin{array}{l}\text { The client explores } \\
\text { the problem with } \\
\text { the counsellor } \\
\text { Counsellor's task }\end{array}$ & $\begin{array}{l}\text { The client gains } \\
\text { insight into the } \\
\text { problem }\end{array}$ & $\begin{array}{l}\text { The client decides on } \\
\text { an action plan }\end{array}$ \\
\hline $\begin{array}{l}\text { To assist the client } \\
\text { to ventilate the } \\
\text { problem }\{\text { tell his/ } \\
\text { her story\} }\end{array}$ & $\begin{array}{l}\text { To assist the client in } \\
\text { exploring issues } \\
\text { related to the onset } \\
\text { and the } \\
\text { maintenance of the } \\
\text { problem }\end{array}$ & $\begin{array}{l}\text { To help client set } \\
\text { goals and } \\
\text { brainstorm } \\
\text { strategies to } \\
\text { achieve goals. To } \\
\text { help clients to } \\
\text { decide on action } \\
\text { plan }\end{array}$ \\
\hline $\begin{array}{l}\text { Goal } \\
\text { In assisting the } \\
\text { client to ventilate } \\
\text { the problem is } \\
\text { defined and client } \\
\text { feels listened to. } \\
\text { Clients who are } \\
\text { helped to tell their } \\
\text { stories will learn } \\
\text { about themselves. }\end{array}$ & $\begin{array}{l}\text { To help the client to } \\
\text { achieve deeper } \\
\text { level of } \\
\text { understanding of } \\
\text { the problem. }\end{array}$ & $\begin{array}{l}\text { To help the client to } \\
\text { translate his/ her } \\
\text { goal to action plan. }\end{array}$ \\
\hline $\begin{array}{l}\text { Skills required } \\
\text { Attending, } \\
\text { listening, showing } \\
\text { empathy, asking } \\
\text { questions }\end{array}$ & $\begin{array}{l}\text { Probing, offering } \\
\text { information, } \\
\text { setting goals }\end{array}$ & $\begin{array}{l}\text { Brainstorming, } \\
\text { sorting pros and } \\
\text { cons, monitoring } \\
\text { progress, ending the } \\
\text { session }\end{array}$ \\
\hline
\end{tabular}

\section{Methods}

Participants

Four of the 11 NGOs employing facility-based lay counsellors to provide ARV adherence support in the Western Cape were randomly selected to take part in the larger study, that is, the implementation of the Options for Health: Western Cape intervention. All agreed to take part. Together these 4 NGOs employed 39 lay ARV adherence counsellors located within 21 ARV clinics around Cape Town. All 39 of these counsellors agreed to take part in this phase of the evaluation. The number of NGOs and counsellors taking part in this sub-study was thus determined by the sample size requirement for the larger study. 
Counsellors self-completed demographic forms. Three experienced data collectors attended the clinics during May 2009 to collect audio-recordings of counselling sessions conducted by lay counsellors with non-adherent patients ( $>18$ years old). Patients sent for adherence counselling are those who are suspected of having poor adherence as the result of a pill count, missed clinic visit/s, an increase in viral load and/or decrease in CD4 count. Such patients are identified and referred for counselling mainly by ARV clinic nurses, and sometimes by doctors and patient advocates (where present). Data collectors attended each clinic and recruited all patients referred for adherence counselling until recordings of three counselling sessions had been received from each counsellor, or until the end of the data collection period was reached. Recorded sessions were individual (as opposed to couple) counselling sessions. Counsellors were provided with vouchers to the value of US $\$ 2.50$ for a local grocery chain in return for each counselling session recorded. Data collectors did not sit in on counselling sessions, and patients were not provided with incentives for allowing their sessions to be recorded. Ethical approval for the study was granted by the Faculty of Health Sciences' Human Research Ethics Committee at the University of Cape Town.

\section{Data Analysis}

Recordings were transcribed verbatim and translated from Xhosa or Afrikaans into English where necessary. A random selection of 10 translations was independently checked for accuracy. Analysis was based on the methods of content analysis [34]. Some codes were predetermined by the researchers and represented particular counselling micro- skills (e.g. "open question", "simple reflection") and activities (e.g. "giving information", "brainstorming"). Other codes were developed on the basis of a first review of the transcripts (e.g., "missed opportunity for reflection", "confrontation"). Specific micro-skills and activities were then grouped according to the stage of Egan's model they could be associated with, such that codes that could be applied to text included "exploration: open question", "understanding: goal setting", "action: advice" etc. Units of analysis were counsellor utterances, defined as complete thoughts (e.g. Why didn't you tell your father that now you are stopping your medication, not taking it anymore?). Codes associated with each stage of Egan's model were then tallied across all transcripts. Two coders coded 19 transcripts each. The first author conducted the analysis and reviewed the coding on all 38 transcripts. The last phase of the analysis involved a read-through of each transcript in its entirety in order to develop a "feel" for the counsellors' manner and style of communication.

\section{Results}

A total of 66 recordings were collected from 32 of the 39 counsellors. Recordings from two counsellors who had provided only one each were excluded from the analysis.

One had been cut-off early in the session, and the other contained evidence that the counsellor had conducted the consent procedure. Originally all transcripts were intended to be analysed but a restriction on resources early on in the analysis necessitated a revision of the sampling strategy. As such, one counsellor had three transcripts analysed, six counsellors had two transcripts analysed each and the remaining 23 had only one randomly selected 
transcript analysed each. In total 38 transcripts representing the work of 30 counsellors were analysed.

\section{Participant Demographics}

The majority of counsellors were female $(\mathrm{n}=26)$ and first language Xhosa speakers $(\mathrm{n}=24)$. Four counsellors were first language Afrikaans speakers, and the remaining two were English. Despite the requirement that lay counsellors be in possession of a Grade 12 certificate, 7 of 30 counsellors had dropped out of school in Grade 10 or 11 . The majority of counsellors $(n=23)$ had up to 5 years of counselling experience in the field of HIV (range from 1 to 10 years), and up to 2 years of experience in ARV adherence counselling specifically $(n=23)$ (range from 1 to 4 years).

While all 30 counsellors had been trained by ATICC in adherence counselling, not all counsellors had taken part in the two courses required to practice as HCT counsellors. Four counsellors had not taken part in the 10 day HIV/ AIDS/ STI/TB Information Course, and six counsellors had not completed the 10 day intensive counselling course (reason unknown).

\section{Counselling Style}

Counsellors assumed the role of expert in all 38 counselling sessions analysed, controlling the direction of the session and relying primarily on their own knowledge and informationgiving in addressing clients' non-adherence. In reading through the transcripts in their entirety, three styles of interaction were evident. Of the 30 counsellors, $20 \%(n=6)$ conducted their sessions in a paternalistic manner, questioning clients in the manner of an interrogation, confronting, reprimanding and providing information as if they were "testing" the client. Another $17 \%$ of counsellors $(n=5)$, while polite, came across as being overwhelmingly business-like in their approach in that they displayed very little or no empathy and interest in the client and focused on fact-finding and giving information and advice. The counselling style of the remaining $63 \%$ of counsellors $(n=19)$ was less distinctive. While these counsellors engaged in instances of moralising, confronting, warning, interrogation and paternalism, they came across as being reasonably friendly and polite in general. These counsellors engaged with, and displayed interest in, the client and the client's problem to varying extents. Egan's Model Stage 1: Opening the Session and Exploration

In stage 1 and after opening the session, the counsellors' task is "to assist the client to ventilate the problem" using their micro-counselling skills. A total of 306 speech acts were coded and associated with this stage. In opening the counselling session, six counsellors (20 \%) were described as being confrontational and/ or patronising, for example:

Counsellor: Cindy, I am of the understanding that you are now late, a month late (for your clinic visit)....and I hope that it does not happen again because this is for your health.

Open questions are considered an appropriate way to open a session because they provide the opportunity for the client to define the issue [35]. Nineteen counsellors (63\%) used an open question at the beginning of the session to explore the referral problem, and this was well done in most cases. For example: 
Counsellor: Sister says you haven't taken your tablets as you are supposed to, what went wrong then? (Counsellor 7, Afrikaans)

The use of closed-ended questions is appropriate for gaining clarity and eliciting specific detail, however counsellors generally relied on closed-questions following the opening question: a ratio of 3.3 closed questions for each open question was calculated for this stage. Seven counsellors (23\%) engaged in series of closed-ended questioning that appeared interrogative, with one counsellor asking as many as 30 closed questions consecutively. One counsellor explored the clients' referral problem particularly well and displayed a skilled use of open and closed questions:

Counsellor: Okay, tell me how are you finding the treatment from when you started taking it? Maybe while you were pregnant up until after you gave birth?

Client: Wait, I was pregnant but I didn't notice anything while taking it, I mean I didn't have a problem, I didn't get sick.

Counsellor: Oh, you didn't have a problem?

Client: huh uh (no), but now I got sick and I had a cramp and I am always having a headache after I gave birth.

Counsellor: Okay, but that didn't disturb you in taking the pills?

Client: It disturbed me a little now that I've come to get them.

Counsellor: What exactly disturbed you?

Client: It's stress you see, the stress of thinking that you are sick and what is making you sick...

(Counsellor 15, Xhosa)

In total 58 simple reflections were associated with this stage in 21 sessions (an average of 3 per session). The majority of these (62 \%) were well done, however the remaining $38 \%$ of reflections were merely repetitions of the client's words (parroting) and did little to facilitate understanding. No complex reflections were coded for this stage. Seven counsellors (23\%) did not engage in an exploration of the referral problem before going on to provide information as a part of stage 2 .

\section{Egan's Model Stage 2: Understanding}

In stage 2 the counsellors' task is "to assist the client in exploring issues related to the onset and the maintenance of the problem". Activities associated with this stage include probing, offering information and setting goals (Table 2). A total of 1,039 speech acts were coded and associated with stage two. Again counsellors relied on the use of closed questions in this stage: a ratio of 3.1 closed questions for each open question (3.1:1) was calculated.

Complex reflections are an advanced counselling skill and ATICC trainers acknowledge that most lay counsellors will find this skill difficult to implement (Table 1). Three complex reflections were observed in three separate sessions. More than half (72\%) of simple reflections associated with this stage were used for fact-checking and were presented in the form of closed-questions. The remaining $28 \%$ of simple reflections represented parroting. (Most reflections were thus of content as opposed to feeling). In addition, 26 "missed 
opportunit(ies) for reflection" were coded, the majority (58\%) of which were related to statements made by clients which revealed underlying emotions such as guilt, sadness and pain. For example:

Counsellor: So, and why, can you tell me why did you stop your medication?

Client: Because also the doctor here told me to leave this clinic and I should never ever come back to this clinic, she doesn't want me here.

Counsellor: Hmm? Okay I understand that, but remember when you first started did they explain to you how important is this medication? (Counsellor 28, English)

Forty-two statements were coded as confrontational in this stage. These were made by almost half (43\%) of counsellors. The majority of these counsellors (69\%) were confrontational in more than one instance, with one counsellor making as many as 12 such statements in one session. For example:

Counsellor: Okay sister...so I will ask you to do what next time? To pull up your socks so you don't meet with meagain. (Counsellor 2, Xhosa)

Counsellor: Okay, in all that you are saying there is nothing that satisfies me.and you must know that by not speaking the truth. I don't know if you (did) get the pills or (if) you didn't get, and I don't want to believe what you are saying. There is nothing here to convince me that you have taken your treatment. (Counsellor 16, Xhosa)

In addition, 14 separate statements were coded as judgemental. These were made by 10 counsellors (33\%), six of whom had also made confrontational statements. Half of these counsellors $(n=5)$ used more than one judgement per session. The statement below is an example of one coded as judgemental:

Counsellor: It amazes me that you are forgetting (to takeyour pills) considering you started (treatment) in 2007, 2008 and it's 2009 now. (Counsellor 19, Xhosa)

In total, 378 instances of information-giving were coded across all 38 transcripts (an average of 10 per session). Only $4 \%$ of information giving was coded as inappropriate because it did not relate to the focus of the session and/ or was not applicable to the clients' situation. The majority (75\%) of information was appropriate (in that it was relevant to the clients' situation) and well-given (respectfully and in digestible "chunks"); $21 \%$ was appropriate but poorly-given. "Poorly given" referred to instances of information that involved many concepts being introduced in large indigestible 'chunks', was technically incorrect, involved stigmatising language or insensitive statements regarding illness and death, was delivered in a patronising way or was unclear. For example:

Counsellor: It's important to be adherent, to know what will happen when you forget your pills because... once you are drug resistant... it's not easy to say, now brother there's nothing we can do, now go home and wait for the day. (Counsellor 2, Xhosa)

Counsellor: As I explained to you that if you don't take (your ARVs) at the right time, really the virus increases and the pills won't help, do you understand? The virus increases and multiplies and now that you didn't take the medication within those 10 min it will equate to weeks do you understand? (Counsellor 19, Xhosa) 
The activity of goal-setting is key to the change process in Egan's model as clients are encouraged to move away from current difficulties by imagining what the future could look like [20, 29]. By describing what they need or want for their future, clients' set the agenda for change [20]. None of the 38 counselling sessions analysed in this study contained evidence of goal-setting in relation to the clients' adherence or health.

\section{Egan's Model Stage 3: Action and Ending the Session}

In Stage 3 the counsellors' task is to "help the client to. brainstorm strategies to achieve goals" and to "help clients decide on an action plan" (Table 2). Skills include brain- storming, sorting pros and cons and ending the session.

Brainstorming provides a pool of potential strategies from which the client can choose a plan for change that they feel best fits their resources, environment and timetable [20]. None of the 30 counsellors in this study facilitated the development of more than one strategy for improving their clients' adherence. No counsellors encouraged clients to consider the pros and cons of various courses of action. Six of 30 counsellors (20\%) asked their client for their own ideas as to how they might overcome the barrier to their adherence. In two cases however, this constituted a superficial attempt to involve the client in the counselling process.

The following example is from a session with a mother whose child is on ARVs:

The remaining 24 counsellors ( $80 \%$ ) offered information and/ or their own advice. Advice related to strategies for overcoming barriers to adherence included the use of reminders and pill boxes, rescheduling treatment times, planning pill-taking around work and travel and attending the clinic before scheduled visit dates if necessary. In many cases the advice appeared to be appropriate to what was known about the clients' situation. In some cases though, counsellors minimised or neglected to take into account the difficulties associated with the course of action they were recommending, for example:

Counsellor: So as the child defaulted what are your plans so that what ha(s) happen(ed) cannot happen again?

Client: I am going to stop working.

Counsellor: But things are important now as the child is going to start treatment again... when a child is using ARV's the one (that is) supposed to stay in the fridge must be in the fridge. The one (that) stays out of (the) fridge, it is important not to place direct (in) the sun... (Counsellor 12, Xhosa)

Counsellor: (regarding the difficulty experienced by the client in getting time off work to attend the clinic) So it's important to takeyour medication every day okay, not to default even if your manager ask you to, tells you that you can't (leave work), then you just tell him that you need to come to the clinic, it is very urgent because of your health okay? (Counsellor 26, English)

Instances of advice were regularly intermingled with instances of information-giving, and during the analysis it became clear that the provision of information was a technique being used by counsellors to encourage clients to adhere. Advice is underlined in the following example: 
Counsellor: Let's say you drink a tablet and you throw up half an hour after that, then you don't have to anymore because it has dissolved in your blood. but you must always try. no matter how ill you feel, you must still drink your tablets because. what will happen is that your body will build up a resistance right? (Counsellor 7, Afrikaans)

In addition to interspersing information with advice, some counsellors employed warnings around the consequences of non-adherence and not taking ARVs seriously. Another technique used by some counsellors was to minimise the difficulty associated with behaviour change:

Counsellor: You have to ask yourself the question, whatis most important to me, right? Client: Yes.

Counsellor: In this instance, your health is . very important, so you must invest in your health by taking (your treatment), that's all you have to do... I don't think that's asking too much. I'm not saying your concerns are not... important... but what I'm asking of you here now, it doesn't take a lot of effort.

Client: Yes

Counsellor: We are only asking you to take your tablets every day .and it's not hard work to do that.

Client: $\quad$ To do that, that's true, yes

Counsellor: It's not difficult. You just take it out and swallow it, so that you can enjoy better health and go back to work. (Counsellor 17, Afrikaans)

Finally counsellors engaged in moralising and appealed to what they assumed to be important to the client in order to encourage behaviour change:

Counsellor: If you already have (HIV) you must know the ways of accepting it, to accept is (to know) that it's not curable, you must look forward, life is going on, do you have children? Client: Yes I have a child.

Counsellor: You must know that you are living for your child, you must (know) that you are looking after him and he needs to be raised. (Counsellor 18, Xhosa)

Theoretically, moralising is considered inappropriate within a counselling relationship [20].

Overall impression: Progression through the counselling session

The results regarding the skills and techniques used by counsellors presented above provide a fragmented picture of counselling sessions. In order to illustrate the progression of counselling sessions, Box 1 presents three randomly selected counselling sessions described in terms of the techniques and phases used by the counsellor in moving through the session. The reliance on the provision of information for encouraging adherence is evident in these, as is the directive nature of the sessions.

\section{Discussion}

Counsellors displayed good knowledge around HIV and ARV treatment and instances of good counselling technique were observed, however counsellors' practice was not consistent with a 
client-centred approach to counselling. Counsellors contravened core principles of client-centred counselling such as the demonstration of respect and positive regard by issuing warnings, moralising, casting judgements and patronising clients. Confrontation, as an advanced counselling skill, is aimed at drawing attention to in-congruencies in clients' speech in a supportive manner [36]. In this study confrontation was used inappropriately and expressed judgement and condescension. Overall clients were not treated as collaborators in the problem-management process. Instead the counsellor-client relationship conformed to that of the traditional patient-provider relationship, characterised by high provider control and authority and where the patients' role is passive and dependant [37].

While not designed as an intervention for improving ARV adherence, Egan's model features many of the strategies identified in the literature as being successful in promoting ARV adherence. For example, in applying the model to the problem of non-adherence, stages 2 and 3 would focus on exploring the barriers to optimal adherence and brainstorming potential strategies for managing these. In this study counsellors' practice did not adhere to the stages and activities associated with Egan's model, and stage 3 was that stage most lacking. Some counsellors did not explore the referral problem of non-adherence before going on to give information, and no counsellors engaged clients in setting goals for their adherence or their health. For Egan [20], goals are of great motivational value and provide clients with incentives to search for strategies to achieve them. Goal-setting triggers action [20] and is thus an important link between stages 2 and 3 in the model. Goal-setting has a become a feature of many health care interventions, and there is some evidence that suggests it is a useful method for facilitating positive behaviour change in relation to over-weight management, diet and physical activity [38-40] and also alcohol use [41]. In terms of chronic disease there is some research around the efficacy of goal-setting for diabetes control, however the goals are generally related to diet and exercise (e.g. 42, 43) as opposed to medication adherence. While there is no evidence for the efficacy of goal-setting as a strategy for promoting medication adherence, the evidence for other outcomes suggests that it would have a positive effect on the efficacy of Egan's model.

Box 1 Examples of counselling sessions, described in terms of the phases and techniques used by counsellors

Counsellor 17 commenced the session in a friendly manner, questioned the client around the reason for her non adherence, gave information on the consequences of non-adherence (drug resistance and 2nd line treatment) and warned that there was no 3rd line of treatment. The counsellor went on to advise that it was important to take the ARVs and minimised the difficulties associated with ARVs and pill-taking, and then questioned the client around her income and work, alcohol, drug and condom use. Before ending the session the counsellor reminded the client of the contract (and promise) she had made with the clinic when she initiated ARV treatment (this was to take her treatment correctly). The counsellor thanked the client, thereby ending the session.

Counsellor 25 greeted the client and explored the reason for the clients' non-adherence, which was because of the development of a side- effect. The counsellor went on to give information about side-effects and advised the client not to stop taking the pills and to 
come into the clinic, before giving information on the consequences of non-adherence (increased viral load, drug resistance). The client argued that s/ he did not want to take the particular ARV causing the side-effect, in response to which the counsellor re-issued the advice to come into the clinic and informed the client that the doctor would "cure it". The counsellor gave information on the benefits of ARVs (increased CD4 count and lowered viral load) and moralised ("do you want to live a long life with your children?"). The counsellor gave information in response to questions asked by the client around his/ her pill-taking schedule, and again advised the client to come into the clinic when s/he experienced any problems. The counsellor thanked the client, thereby ending the session. Counsellor 32 began the session by confronting the client and accusing her of being "careless" because she did not arrange for someone to collect her treatment when she couldn't make her scheduled visit date. The counsellor went on to give information on the consequences of non-adherence (increased viral load, TB, drug resistance). The counsellor then asked the client to promise that she wouldn't forget to take her ARVs because it was important. The counsellor did not end the session (or switched off the recorder before ending the session).

Brainstorming and assessing "pros and cons" are other important activities in Egan's model [20], and in which counsellors did not engage. Brainstorming stimulates creative thinking around strategies for goal-accomplishment, and engages clients in coming up with and evaluating possible ways forward [20]. Instead counsellors in this study employed directive techniques in order to address clients' non-adherence, most commonly providing information and advice. Interestingly the use of these techniques has also been identified among HIV nurse-counsellors working in Soweto, South Africa [44]. The provision of advice within healthcare consultations can be met with patient resistance, superficial agreement or rejection [45-48]. Wilson et al. [49], in examining United States' physicians ability to perform effective adherence counselling, found that much of physicians speech associated with problem-solving was directive in nature; physicians urged patients to undertake certain actions. This approach was shown to be ineffective in improving ARV adherence [49]. However, as Barnighausen et al. [13] suggest, such evidence may not be relevant to SSA settings. For example, in examining the applicability of client-centred counselling to non-Western cultures, Laungani [50] teases out the theoretical assumptions underlying the approach. He argues that the idea of a relationship between a client and counsellor that is equal stems from the fundamental notion of Individualism, a concept that is of little value among other (e.g. community-based) societies. Many SSA cultures have been characterised as collectivist and as favouring deference to authority [51]. In this context, it is possible that information and advice given by a person of authority is an effective way in which to address non-adherence. Participants interviewed in a study in Tanzania described advice from service providers as one of five factors positively influencing their motivation to adhere to their ARV regimen; patients perceived providers as referent authorities whose advice they should follow 
without question [52]. These patients were highly adherent and relatively new on treatment however, and are unlikely to represent the larger population of people on treatment.

In evaluating ARV adherence counsellors' performance, it is important to acknowledge the barriers to client-centred counselling practice (required by Egan's model) that are associated with the clinic setting. For example the role of HIV counsellors is related to specific behavioural aims [19], and HIV counselling necessarily includes an educative component. In addition counsellors are often under pressure to see a large number of patients in a short amount of time, and it has been suggested that time pressure contributes to shaping HIV lay counsellors' practice in a more goal-oriented, urgent and directive direction [53]. Counselling for adherence is also not voluntary, thus eliciting client participation in brainstorming and problem-solving is potentially more challenging (particularly if the counsellor is perceived as an expert who should be deferred to). It is possible that client resistance contributes to the adoption of a directive approach. In addition counsellors are not provided with refresher training or with regular supervision focusing on counselling skills and case management.

In summary, lay ARV adherence counsellors' practice did not conform to what is known about effective counselling interventions for ARV adherence support. Counsellors' practice was generally not client-centred and was inconsistent with the stages of Egan's "Skilled Helper" model. Activities associated with problem-management were those most lacking. At a minimum, counsellors should be provided with regular supervision focusing on micro-counselling skills and the avoidance of inappropriate strategies such as moralising, warning and confrontation. Supervision should also include case management where the 3 stages of Egan's model, and problem-management techniques in particular, are revised and applied. It is also worth investigating other counselling models that are focused specifically on health behaviour change and which might be more appropriate for the primary health care setting. Increased training and supervision activities would be required before the question as to whether lay counsellors are able to effectively implement client-centred and problem-management counselling techniques could be answered however. Further questions raised by this study are around the efficacy of the directive and information-giving approach to adherence counselling, and the appropriateness of client-centred counselling strategies in this setting. Future research should focus on the cultural applicability of both potential counselling models and models or theories of behaviour change, and should be used to inform the implementation of an adherence support service that is culturally responsive and meets the needs of recipients.

Acknowledgments J oanne Croome and Michelle Wanless for their work on the coding of data. Nontobeko Mdudu for data collection. 


\section{References}

1. Ammaranond P, Sanguansittianan S. Mechanism of HIV anti- retroviral drugs progress toward drug resistance. Fundam Clin Pharmacol. 2011. doi:10.1111/j.1472-8206.2011.01009.x.

2. Chan KC, Wong KH, Lee SS. Universal decline in mortality in patients with advanced HIV-1 disease in various demographic subpopulations after the introduction of HAART in Hong Kong. HIV Med. 2006; 7:186-92.

3. Bangsberg DR, Perry S, Charlebois ED, et al. Non-adherence to highly active antiretroviral therapy predicts progression to AIDS. AIDS. 2001;15(9):1181-3.

4. Bangsberg DR, Hecht FM, Charlebois ED, et al. Adherence to protease inhibitors, HIV-1 viral load, and development of drug resistance in an indigent population. AIDS. 2000;14:357-66.

5. Lima VD, Harrigan R, Bangsberg DR, et al. The combined effect of modern highly active antiretroviral therapy regimens and adherence on mortality over time. J Acquir Immune Defic Syndr. 2009;50:529-36.

6. Amico KR. Standard of care for antiretroviral therapy and retention in care from the perspective of care providers attending the 5th international conference on HIV treatment adherence. J Int Assoc Physicians AIDS Care. 2011;10(5):291-6.

7. Harman JJ , Amico KR, J ohnson BT. Standard of care: promoting antiretroviral adherence in clinical care. AIDS Care. 2005; 17(2):237-51.

8. Simoni J M, Pearson CR, Pantalone DW, et al. Efficacy of interventions in improving highly active antiretroviral therapy adherence and HIV-1 RNA viral load: a meta-analytic review of randomized controlled trials. J Acquir Immune Defic Syndr. 2006;43(S1):S23-35.

9. Haynes RB, Ackloo E, Sahota N et al. Interventions for enhancing medication adherence. Cochrane Database Syst Rev. 2008; 2: CD000011.

10. Kripalani S, Yao X, Haynes RB. Interventions to enhance medication adherence in chronic medical conditions: a systematic review. Arch Intern Med. 2007;167:540-50.

11. Amico KR, Harman JJ, Johnson BT. Efficacy of antiretroviral therapy adherence interventions: a research synthesis of trials, 1996 to 2004. J Acquir Immune Defic Syndr. 2006;41(3):285-97.

12. Rueda S, Park-Wyllie LY, Bayoumi A et al. Patient support and education for promoting adherence to highly active antiretroviral therapy for HIV/AIDS. Cochrane Database Syst Rev. 2006;3: CD001442.

13. Barnighausen $\mathrm{T}$, Chaiyachati $\mathrm{K}$, Chimbindi $\mathrm{N}$, et al. Interventions to increase antiretroviral adherence in sub-Saharan Africa: a systematic review of evaluation studies. Lancet Infect Dis. 2011;11(12):942-51.

14. De Bruin M, Viechtbauer W, Hospers HJ. Standard care quality determines treatment outcomes in control groups of HAART- adherence intervention studies: implications for the interpretation and comparison of intervention effects. Health Psychol. 2009;28(6): 668-74. 
15. Chung $\mathrm{MH}$, Richardson $\mathrm{BA}$, Tapia $\mathrm{K}$ et al. A randomised controlled trial comparing the effects of counselling and alarm device on HAART adherence and virologic outcomes. PLoS Med. 2011;8(3):e1000422.

16. J ohnson A, Witt H. Adherence to ART practices in resource- constrained settings. 2007. Submitted to the U.S. Agency for international development by the rational pharmaceutical management plus program. Arlington, VA: Management Sciences for Health.

17. Lewin SA, Dick J, Pond P et al. Lay health workers in primary and community health care. Cochrane Database Syst Rev. 2005; CD004015.

18. Mash R, Baldassini G, Mkhatshwa $\mathrm{H}$, et al. Reflections on the training of counsellors in motivational interviewing for programmes for the prevention of mother to child transmission of HIV in sub-Saharan Africa. SA Fam Pract. 2008;50(2):53-9.

19. Evangeli M, Engelbrecht S-K, Swartz L, et al. An evaluation of a brief motivational interviewing training course for HIV/ AIDS counsellors in Western Cape Province, South Africa. AIDS Care. 2009;21(2):189-96.

20. Egan G. The skilled helper: a problem-management and opportunity-development approach to helping, 7th ed. Belmont: Brooks/Cole Thomson Learning; 2002.

21. Richter LM, van Rooyen H, Solomon V, et al. Putting HIV/AIDS counselling in South Africa in its place. Soc. Transit. 2001; 32(1):148-54.

22. Hall L, Lloyd S. Surviving childhood sexual abuse: a handbook for helping women challenge. 2nd ed. London: Falmer Press; 1993.

23. Kidd J. Career development work with individuals. In: Woolfe R, Dryden W, editors. Handbook of counselling psychology. London: Sage; 2003. p. 461-80.

24. Coles A. Counselling in the workplace. Maidenhead, IK: Open University Press; 2003.

25. Franklin L. An introduction to workplace counselling: a practitioners guide. Basingstoke: Palgrave Macmillan; 2003.

26. Hudson-Allez G. Time-limited therapy in a general practice setting. London: Sage; 1997.

27. Arnold E, Boggs K. Interpersonal relationships: Professional communication skills for nurses, 2nd ed. London: Routledge; 1995.

28. Freshwater D. Counselling skills for nurses, midwives and health visitors. Maidenhead: Open University Press; 2003.

29. Newnham-Kanas C, Morrow D, Irwin J. Motivational coaching: a functional juxtaposition of three methods for health behaviour change: motivational interviewing, coaching, and skilled helping. Int J Evid Coach Mentor. 2010;8(2):27-48.

30. Centers for Disease Control and Prevention. Recommendations for HIV testing services for inpatients and outpatients in acute- care hospital settings; and technical guidance on HIV counselling. MMWR. 1993; 42(RR-2):8-17.

31. Pienaar D, Myer L, Cleary S, et al. Models of care for antiret- roviral service delivery. Cape Town: University of Cape Town; 2006.

32. Mpofu E. Theories and techniques for counselors applied to African settings. Harare: College Press; 2006. 
33. Kuntze J, van der Molen HT, Born M. Progress in mastery of counselling communication skills: development and evaluation of a new instrument for the assessment of counselling communication skills. Eur Psychol. 2007;12(4):301-13.

34. Graneheim UH, Lundman B. Qualitative content analysis in nursing research: concepts, procedures and measures to achieve trustworthiness. Nurse Educ Today. 2004;24:105-12.

35. Daniels T, Ivey AE. Microcounselling: making skills training work in a multicultural world. Springfield: Charles C Thomas; 2007.

36. Strong T, Zeman D. Dialogic considerations of confrontation as a counseling activity: an examination of Allen Ivey's use of confronting as a microskill. J Couns Dev. 2010;88:332-9.

37. Everett-Murphy K, Paijmans J, Emmelin M, et al. Scolders, carers or friends: South African midwives' contrasting styles of communication when discussing smoking cessation with pregnant women. Midwifery. 2011;27(4):517-24.

38. Pearson ES. Goal setting as a health behavior change strategy in overweight and obese adults: a systematic literature review

examining intervention components. Patient Educ Couns. 2011;87(1):32-42.

39. Cullen KW, Baronowski T, Smith SP. Using goal setting as a strategy for dietary behavior change. J Am Diet Assoc. 2001; 101:562-6.

40. Shilts MK, Horowitz M, Townsend M. Goal setting as a strategy for dietary and physical activity behavior change: a review of the literature. Am J Health Promot. 2004;19(2):81-93.

41. Lozano BE, Stephens RS. Comparison of participatively set and assigned goals in the reduction of alcohol use. Psychol Addict Behav. 2010;24(4):581-91.

42. De Walt DA, Davis TC, Wallace AS, et al. Goal setting in diabetes self-management: taking the baby steps to success. Patient Educ Couns. 2009;77:218-23.

43. Miller CK, Headings A, Peyrot M et al. Goal difficulty and goal commitment affect adoptions of a lower glycemic index diet in adults with type 2 diabetes. Patient Educ Couns. 2012;86(1): 84-90.

44. Stein J , Steinberg M, Allwood C et al. Nurse-counsellors perceptions regarding HIV/ AIDS. Counselling objectives at Baragwanath hospital. In: Sherr L, Catalan J, Hedge B, editors. The impacts of AIDS: psychological and social aspects of HIV infection. Amsterdam: Harwood Academic Publishers; 1997. p. 191-98.

45. Salter C, Holland R, Harvey R, et al. "I haven't even phoned my doctor yet." The advice giving role of the pharmacist during consultations for medication review with patients aged 80 or more: qualitative discourse analysis. BMJ . 2007;334(7603):1011.

46. Kinnell AK, Maynard DW. The delivery and receipt of safer sex advice in pretest counseling sessions for HIV and AIDS. J Con- temp Ethnogr. 1996;24(4):405-37.

47. Rollnick S, Kinnersley P, Stott N. Methods of helping patients with behaviour change. BMJ . 1993;307:188-90. 
48. Heritage J , Sefi S. Dilemmas of advice: aspects of the delivery and reception of advice in interactions between health visitors and first time mothers. In: Drew P, Heritage J, editors. Talk at work. Cambridge: Cambridge University Press; 1992. p. 359-417.

49. Wilson IB, Barton Laws M, Safren S, et al. Provider-focused intervention increases adherence-related dialogue, but does not improve antiretroviral therapy adherence in persons with HIV. J Acquir Immune Defic Syndr. 2010;53(3):338-47.

50. Laungani P. Replacing client-centred counselling with culture- centred counselling. Couns Psychol Q. 1997;10(4):343-52.

51. Beugre CD, Offodile OF. Managing for organizational effectiveness in sub-Saharan Africa: a culture-fit model. Int J Hum Resour Manag. 2001;12:535-50.

52. Watt MH, Maman S, EarpJ , et al. "It's all the time in my mind": facilitators of adherence to antiretroviral therapy in a Tanzanian setting. Soc Sci Med. 2009;68:1793-800.

53. Richter L, Durrheim K, Griesel R, Solomon V, van Rooyen H. Evaluation of HIV/AIDS counselling in South Africa. Contract report submitted to the Department of Health, Pretoria; 1999. 